\title{
The Tutorial Video and Improving Service Value in The Broadcasting Laboratory of Universitas Multimedia Nusantara
}

\author{
Agus Syawal $^{1}$, Johny N. Prihanto ${ }^{2}$, So Yohanes Jimmy ${ }^{3}$ \\ \{agus.syawal@student.umn.ac.id ${ }^{1}$,johny.natu@umn.ac.id ${ }^{2}$,yoh.jimmy@gmail.com ${ }^{3}$ \} \\ Faculty of Management, Universitas Multimedia Nusantara, Indonesia ${ }^{1,2,3}$
}

\begin{abstract}
The topic in this research is the use of tutorial video in the UMN broadcasting laboratory as its innovation and service improvement. 58\% problems of the laboratory users are difficulty in recognizing the types and they do not know how to use the equipment. Implementation of Digital Maturity Model (DMM) and Digital Transformation Project (DTP) are the problem solving for this case study and will give more benefits for services value. This study uses a quantitative approach, taking questionnaire data regarding the response of the DMM in the laboratory and then The Business Capabilities of the institution. A gap of laboratory services, the current conditions are on average at the emerging level, and the expected future conditions are on average at the leading level. The tutorial video is an effective way of conveying information, these are expected to increase the user satisfaction.
\end{abstract}

Keywords: Digital Transformation, Digital Maturity Model, Customer Experience, Business Capability, Tutorial Video.

\section{Introduction}

Universitas Multimedia Nusantara (UMN) provides a broadcasting laboratory as a facility for student learning activities. Currently, UMN broadcasting laboratory services have been assisted by the existence of a digital-based service application called GAPURA. From this application, users can order and borrow equipment and facilities in the laboratory. Users come from students, lecturers, and university staff.

Table 1 describes the results of an observation of laboratory daily service activities. This observation found the problem that $58 \%$ of users do not know the type of equipment they borrow and also do not know how to use the equipment they are borrowing. This problem becomes important to solve when dealing with effectiveness, service efficiency to the value of service user satisfaction. The questions that arise in this research are:

- How to effectively provide information related to laboratory services?

- How to provide information about the types of laboratory equipment and how to use it?

- How to relate solving this problem and the implementing digital transformation?

- How can this solution provide benefits for users, laboratory service systems, and also for the institution?

Table 1. Results of laboratory service observations

\begin{tabular}{llc}
\hline No & \multicolumn{1}{c}{ Problem Description } & Percentage \\
\hline 1 & Lack of technical information on using tools & $29 \%$ \\
\hline 2 & Less information about equipment & $29 \%$ \\
\hline 3 & Lack of information about the GAPURA & $26 \%$ \\
\hline 4 & Users that ignoring of procedures & $16 \%$ \\
\hline & Total & $100 \%$ \\
\hline
\end{tabular}

(Source: Author, 2020)

To solve this problem, the researcher offers to use video tutorial media as a way to convey related information, especially the explanation of tools and procedures for using equipment in the UMN broadcasting laboratory. Airinei Dinu and Daniel Homocianu [1] write about 25\% of students 
who watch video tutorials before practicum activities get better results than learning by reading books. Then as many as $60 \%$ of the cases of the questionnaires that were distributed, students admitted that video tutorials were very useful and helped support them in their learning. According to Riyana, as cited in Meyta [2], instructional video media is an introductory message in the form of audio and visual offerings in which there are principles, concepts, procedures and application theories that will help provide understanding of learning material.

Munadi, as cited in Sri [3] states that there are practical values in the use of video tutorial media in lectures, including:

a) As a solution to overcome the problem of distance and time limitations.

b) Screening of videos can be repeated many times to improve understanding of a material.

c) The material and information it conveys will be quick to understand and easy to remember.

d) Develops imagination and clarifies things that were not real and can only be imagined to be real and visible.

\section{Literature Review}

The business model canvas (BMC) is used as a guide for aligning the company's strategy with the possibility of implementing digital transformation that will be implemented.

Alexander Osterwalder and Yves Pigneur [4] in their book Business Model Generation explain that a business model is about how a company creates and gets value for itself in addition to delivering products or services to its customers. From this book the researcher also develops 9 building blocks as discussed in the book. This company analysis by researchers is described in an analysis tool using the Business Model Canvas.

The Digital Maturity Model (DMM) is used by researchers to measure the maturity level of digital technology that has been applied in the laboratory. This measurement will determine the current maturity level and make it easier to determine the target maturity level to be achieved in the future. Deloitte [5] explains that the Digital Maturity Model is a framework used to determine the level of maturity and readiness of an organization or company digitally today, and to help build a roadmap for the plans and future of the organization or company.

According to the TM Forum [6], the Maturity Model is a business tool that can use to assess the current status of a company or organization from certain existing capabilities and help them so that it becomes clear which parts need to be changed or improved.

Deloitte and TM Forum describe this measurement into 5 dimensions with 24 sub-dimensions and 110 criterias. The dimensions referred to are Customer, Strategy, Technology, Operation and Culture. Researchers use the five dimensions of the TM Forum and select the sub-dimensions that the authors assume are related and important to be used in DTP to be applied in this study. These dimensions and sub-dimensions are:

1. Dimension Customer, sub-dimension Customer Experience.

2. Dimension Strategy, sub-dimension of Strategic Management.

3. Dimension Technology, sub-dimension Delivery Governance.

4. Dimension Operation, sub-dimension Integrated Service Management.

5. Dimension Culture, sub-dimension Employee Enablement.

The DMM measurement scale, TM Forum [7] states the DMM measurement scale used by TM Forum refers to the level of maturity represented by 5 levels, namely:

1. Initiating, the initial stages and inception of inclusion into business operations.

2. Emerging, more advanced conditions and incorporated into all day-to-day operations.

3. Performing, the organization has set clear goals and formulated a plan that is followed by all parts of the company.

4. Advancing, the organization has expanded its plans and objectives to generate new and innovative ideas.

5. Leading, a condition in which the organization has mastered this field, and has also been considered a thought leader in this field, and regularly leads industry discussions on this topic. 
Business-Capability Map, Denise Cook, as cited in Oluwaseyi [8] states that businesscapability mapping is a modeling process carried out by a business to achieve its goals in terms of its capabilities or capabilities, not just from how to carry out its business processes. Digital Maturity Model (DMM) is an example of a business-capability map that specifically helps companies determine the modeling and process of a company's digital transformation. Marc Lankhorst [9] in his presentation explained that this capability mapping is divided into 3 parts, namely: Strategic Capabilities, Operational Capabilities, and Supporting Capabilities.

The implementation of this DTP with the stages described in table 2 below requires company capabilities in the dimensions of Business management, Product management, Customer care, Asset management, and Business support. These five dimensions are expected to work together so that the goal of achieving DTP implementation will run well.

Table 2. Business-Capability

\begin{tabular}{cll}
\hline \multicolumn{1}{c}{ Capabilities } & \multicolumn{1}{c}{ Dimensions } & \multicolumn{1}{c}{ Categories } \\
\hline Strategic Capability & Business Management & Strategic Management \\
\hline Operational Capability & Product Management & Product Engineering \\
\cline { 2 - 3 } & Customer Care & Customer Service \\
& & Service Channel Management \\
\cline { 2 - 3 } & Asset Management & Asset Inventory Maintenance \\
& & \\
\hline Supporting Capability & Business Support & Facility Management \\
& & IT Management \\
\hline
\end{tabular}

(Source: Author, 2020)

\section{Methodology and Data Analysis}

Continuing the implementation for further analysis including data collection methods and scientific methodologies that will be used, the researcher makes a descriptive analysis that will provide an overview of current and future conditions so that it is known if there are gaps that can be used as opportunities for the development of this digital transformation. Researchers distributed questionnaires and filled in by respondents consisting of laboratory users such as students, lecturers, staff, and also institutional leaders. The number of respondents obtained was 30 respondents. From the lowest score of 1 and the highest of 5, there are 5 levels that the researcher must divide from the maximum value that applies in this questionnaire. So that the category of maturity level can be determined by comparing it with the average values obtained as follows:

- Initiating, if $1.00<$ average value $<1.80$

- $\quad$ Emerging, if $1.80<$ the average value $<2.60$

- Performing, if $2.60<$ the average value $<3.40$

- Advancing, if $3.40<$ the average value $<4.20$

- $\quad$ Leading, if $4.20<$ the average value $<5.00$

As explained in table 3, from this questionnaire the researcher also gets an overview of the current conditions of DMM and the expectations of future conditions from laboratory users. Expectations on the dimensions in this study are expected by respondents as a target for improvement of laboratory services and performance later. 
Table 3. Expectations of laboratory conditions

\begin{tabular}{|c|c|c|c|c|c|c|c|}
\hline \multirow[t]{3}{*}{ No. } & \multirow[t]{3}{*}{ Dimension } & \multicolumn{2}{|c|}{ Current Condition } & \multicolumn{4}{|c|}{ Future Condition } \\
\hline & & \multirow[b]{2}{*}{ Average } & \multirow[b]{2}{*}{ Category } & \multicolumn{2}{|c|}{ Users Expectation } & \multicolumn{2}{|c|}{ Institution Expectation } \\
\hline & & & & Average & Category & Average & Category \\
\hline 1 & Customer & 2,49 & Emerging & 4,37 & Leading & 4,55 & Leading \\
\hline 2 & Strategy & 2,46 & Emerging & 4,45 & Leading & 5 & Leading \\
\hline 3 & Technology & 2,47 & Emerging & 4,38 & Leading & 4,66 & Leading \\
\hline 4 & Operation & 2,48 & Emerging & 4,38 & Leading & 4,66 & Leading \\
\hline 5 & Culture & 2,44 & Emerging & 4,35 & Leading & 4,33 & Leading \\
\hline
\end{tabular}

(Source: Author, 2020)

The five dimensions that represent current conditions in the UMN broadcasting laboratory are expected to increase to the leading level. This is reflected in the average value obtained from the variables assessed in the distributed questionnaires. The Customer Dimension has a mean of 4.37. Then the strategy dimension gets a value of 4.45. The technology, operation, and culture dimensions were respectively 4.38 , and 4.38 , and 4.35 .

Figure 1 illustrates the gap between the current conditions and the expectations of the institution for laboratory development. In order to achieve this condition, efforts are made to implement this DTP so that there is an increase in the level from the present condition to the expected conditions, from the current condition to the future condition.

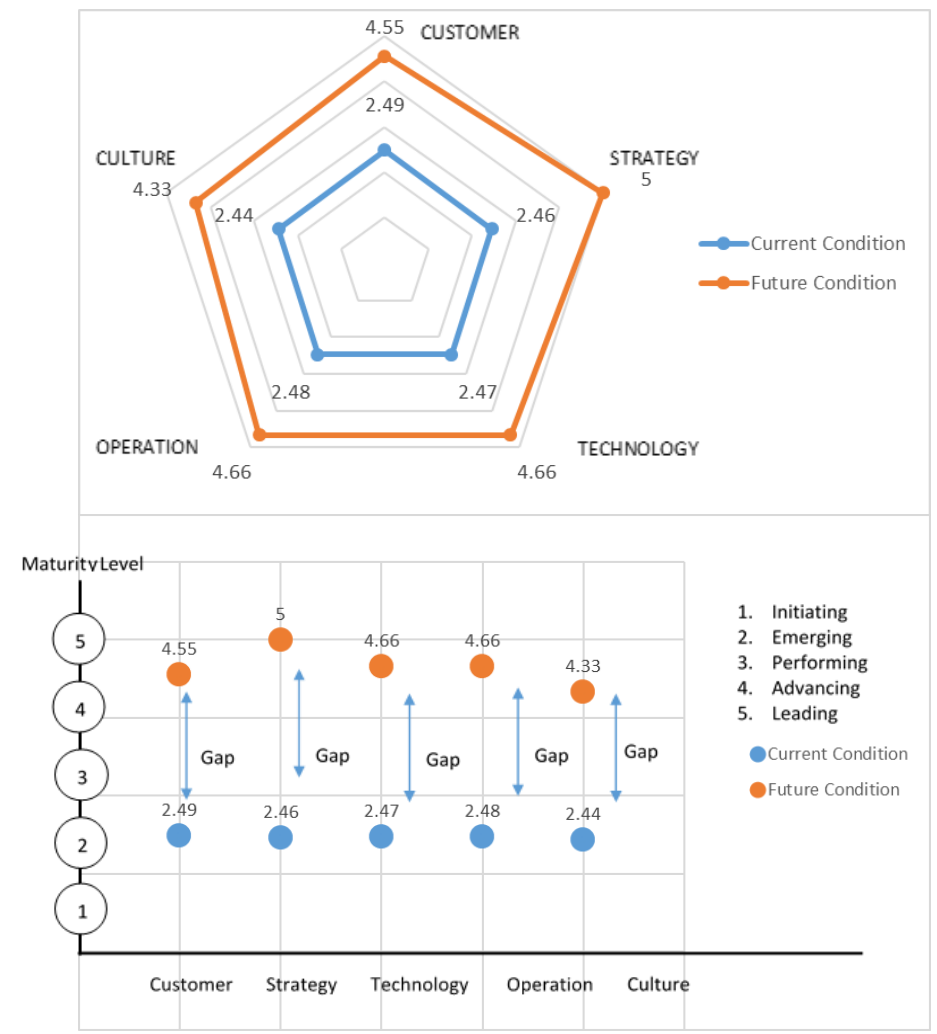

(Source: Author, 2020)

Figure 1. Gap analysis 
It is explained in Figure 2 that this project will be implemented within five months. The five months of this project included planning to disseminate the application of innovations in DTP offered by researchers.

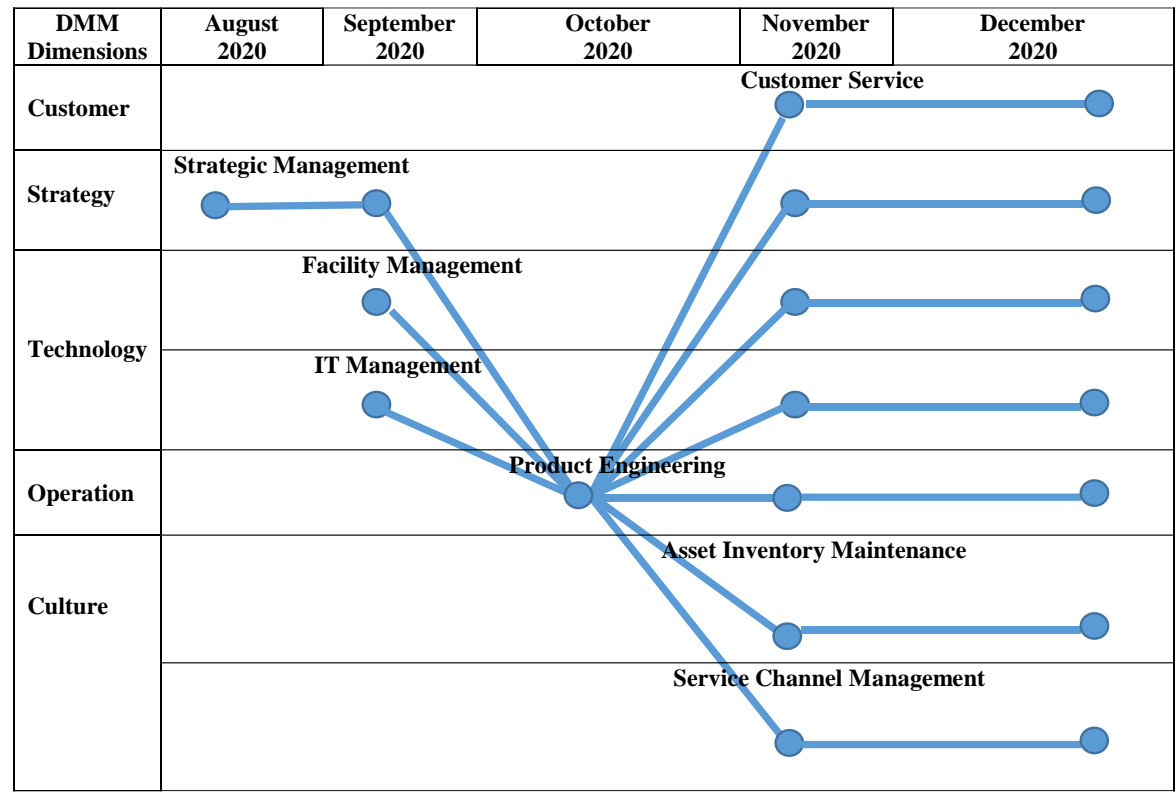

(Source: Author, 2020)

Figure 2. Road map of DTP implementation in UMN Broadcast laboratory

Researchers plan in the first two months of planning and preparation time. The next three months were the stages of making the video, including it in the Gapura application, monitoring the function of the video tutorial feature, socializing the application of the latest features, and creating interactive facilities between users and staff in the GAPURA service provided by the UMN broadcast laboratory.

Table 4. Equipments in the laboratory

\begin{tabular}{clcc}
\hline No & Group of Equipment & Type of Equipment & Quantity \\
\hline 1 & Photography & 28 & 159 \\
2 & Film & 25 & 508 \\
3 & Broadcasting & 12 & 240 \\
4 & Accessories & 41 & 239 \\
& Total & $\mathbf{1 0 6}$ & $\mathbf{1 1 4 6}$ \\
\hline
\end{tabular}

(Source: Author, 2020)

In the process of making this video, a number of 1146 items in the laboratory were grouped into 106 types of equipment for making tutorial videos. Table 4 describes the number of equipment for which the video tutorial will be made. Within 3 months, 8 to 9 tutorial videos will be produced each week to achieve the target of completing 106 tutorial videos in this project. 


\section{Case Study}

UMN has a broadcasting laboratory that serves borrowing facilities and broadcasting practicum equipment. The problem that arises in services in this laboratory is that there are users who do not know the type of equipment and how to use the equipment in the laboratory. The current condition of users can use the application to borrow laboratory equipment and facilities, but they still have to meet laboratory staff just to ask about the type of equipment and how to use it.

With this digital transformation innovation, users no longer have to come or spend time just to find out what kind of equipment is in the laboratory and how to use it. This transformation is carried out not only to overcome the problems but also be able to provide other benefits and contribution to increasing the value of services in the laboratory. Gapura is the name of the digital services application in UMN broadcasting laboratory. The implementation of this digital transformation is making a tutorial video on the Gapura service application.

\section{Research Result and Discussion}

The problem that will be resolved in this research is how to make it easier for users to obtain information related to equipment and technical use of existing equipment in the UMN broadcast laboratory. The solution offered by researchers is to develop digital transformation, especially in the digital service features on GAPURA, the UMN broadcast laboratory service application. The benefits of implementing Digital Transformation in the form of a video tutorial feature in the UMN broadcast laboratory service application are:

Benefits for the users are:

- Service time efficiency

- Cost efficiency for service users

- The effectiveness of knowledge management

- Ease of access

- Minimizing the risk of damage

- As additional lecture material

Benefits for The laboratory staff are:

- Increased service value and performance of department

- Efficiency of manager tasks

Benefits for The institution are:

- Increased level of confidence in prospective new students

- Improving the quality of the institution facilities and services

Blake Morgan [10] gives some data, that companies with a customer experience mindset drive revenue 4-8\% higher than the rest of their industries. Two-thirds of companies compete on customer experience, up from just $36 \%$ in $2010.84 \%$ of companies that work to improve their customer experience report an increase in their revenue. $96 \%$ of customers say customer service is important in their choice of loyalty to a brand.

\section{Conclusion}

This research is a response to problems that arise in service activities in the UMN broadcast laboratory. The problem is about the user's difficulty in obtaining information about the types of tools and how to use an equipment in the laboratory. This study produces a road map that will answer this problem as well as provide results in the form of other benefits related to efficiency, effectiveness, and increased service value. 


\section{Implications and Suggestions For Further Research}

The implication for institutions due to the implementation of DTP is the increased value of laboratory services as evidenced by the improvement of better service and satisfying users. Improving the quality of services and facilities will also increase the value of the institution in the accreditation of higher education institutions and will also have an impact on the interest of prospective new students. From the several benefits resulting from the application of digital transformation in this study, the researcher considers that this research may still have shortcomings, especially on how digital transformation can be further developed and applied in the field of laboratory services. Future research might be able to expand the coverage of the number of respondents and the dimensions in DMM, which in this study only use a few sub-dimensions. The technology such as Artificial Intelligence (AI) could become as a challenge to adopt and to realize in this laboratory services.

\section{References}

[1] D. Airinei and D. Homocianu, "The Importance of Video Tutorials for Higher Education - the Example of Business Information Systems," Qual. Manag. High. Educ. Vol 2, no. December, pp. 345-348, 2010.

[2] M. Pritandhari and T. Ratnawuri, "Evaluasi Penggunaan Video Tutorial Sebagai Media Pembelajaran Semester Iv Program Studi Pendidikan Ekonomi Universitas Muhammadiyah Metro," PROMOSI (Jurnal Pendidik. Ekon., vol. 3, no. 2, pp. 11-20, 2015.

[3] S. Maiyena and V. Haris, "Praktikalitas Video Tutorial pada Matakuliah Eksperimen Fisika untuk Meningkatkan Keterampilan Proses Sains Mahasiswa," J. Ilm. Pendidik. Fis. Al-Biruni, vol. 6, no. 1, p. 75, 2017.

[4] A. Osterwalder, Y. Pigneur, A. Smith, and T. Movement,"Business Model Generation: A Handbook for Visionaries, Game Changers, and Challengers", Wiley, New Jersey.p.14, 2010.

[5] C. Anderson and W. Ellerby, "Digital Maturity Model," Deloitte, no. February, pp. 9-12, 2018.

[6] TM Forum, "Digital Maturity Model Version 2.0/2018”, https://www.tmforum.org/digital-maturitymodel-metrics/model-overview/, [May 19,2020].

[7] TM Forum,"Digital Maturity Model: A blueprint for digital Transformation.” TM Forum White Paper, 2017.

[8] Oluwaseyi Ojo, "Developing Business Capabilities Using COBIT 5", https://www.isaca.org/resources/news-and-trends/industry-news/2017/developing-businesscapabilities-using-cobit-5, January 11, 2017 [August 15, 2020]

[9] Marc Lankhorst, “Archimate 3.0 - Capability Mapping”, https://bizzdesign.com/blog/archimate-3-0capability-mapping/, June 27, 2016 [August 15, 2020]

[10] Blake Morgan, "50 Stats That Prove The Value Of Customer Experience", https://www.forbes.com/sites/blakemorgan/2019/09/24/50-stats-that-prove-the-value-of-customerexperience/\#433d8b7c4ef2, September 24, 2019 [ August 15, 2020]. 